\title{
The effect of temperature reduction on respiratory rate in febrile illnesses
}

\author{
T J D O'Dempsey, B E Laurence, T F McArdle, J E Todd, A C Lamont, B M Greenwood
}

\begin{abstract}
A raised respiratory rate is a useful sign in the diagnosis of pneumonia in children. It was observed that children with malaria and other febrile illnesses may also present with a raised respiratory rate. To determine the extent to which increased body temperature contributes to the raised respiratory rate observed in these children the effect of change in body temperature on respiratory rate was measured in $\mathbf{1 8 6}$ sick Gambian children with a raised respiratory rate, including those with pneumonia or malaria.
\end{abstract}

A temperature dependent effect on respiratory rate of 3.7 breaths per minute per degree centigrade was demonstrated for the whole study cohort, with no significant difference between children with pneumonia or malaria. Twenty three per cent of children with pneumonia whose temperature fell had a final respiratory rate below that currently recommended by the World Health Organisation for the diagnosis of pneumonia.

It is concluded that respiratory rate is to some extent dependent on body temperature in children with febrile illnesses such as pneumonia and malaria, but that this does not alone account for the raised respiratory rate seen in these children. The effect of reduction in body temperature on respiratory rate does not help to distinguish children with pneumonia from those with malaria. A history of recent use of an antipyretic or other measures to control fever is important when evaluating children for possible pneumonia.

(Arch Dis Child 1993; 68: 492-495)

The World Health Organisation (WHO) guidelines for the management of children with acute respiratory infections recommend that children who present with cough, difficulty in breathing and a raised respiratory rate $(\geq 60 / \mathrm{min}$ age $<2$ months, $\geq 50 / \mathrm{min}$ age $2-11$ months, $\geq 40 / \mathrm{min}$ age 12-60 months), or indrawing should be treated for pneumonia with antibiotics. ${ }^{1}$

When we used these age adjusted respiratory rates to identify children attending clinics for those under 5 years with possible pneumonia, we observed that many children with a raised respiratory rate had malaria and, frequently, also had cough or difficulty in breathing, causing diagnostic difficulties for peripheral health care workers (T J D O'Dempsey et al, unpublished). We hypothesised that in children with malaria a raised respiratory rate is due predominantly to fever, while in children with pneumonia it reflects, at least in part, compromised pulmonary function. If this hypothesis is correct it would be anticipated that, when treated for fever, children with malaria would demonstrate a greater fall in respiratory rate per unit fall in temperature than children with pneumonia, and that the response to treatment of fever might help to differentiate between these two common conditions.

In this paper we report the results of a study that indicates that this is not the case, and that the raised respiratory rate of children with either malaria or pneumonia responds in a similar manner to reduction of fever.

\section{Patients and methods}

The study was conducted in Upper River Division, The Gambia, during a period of high malaria transmission (August-October, 1990) and during a period of low malaria transmission (April-May, 1991).

Children who attended clinics for those under 5 years or outpatient clinics at health centres and trekking stations were referred to the Medical Research Council (MRC) field station at Basse if their respiratory rate was raised and if the mother felt that the child was ill. On arrival at the field station a trained nurse obtained a history, recorded the axillary temperature over a period of three minutes and, when the child was settled, counted the respiratory rate by observing the movement of the lower chest and upper abdomen for one minute. Oxygen saturation was measured using a Nellcor N-200E pulse oximeter.

Children with a temperature of $38.0^{\circ} \mathrm{C}$ or greater were given a single standard dose $(15 \mathrm{mg} /$ $\mathrm{kg}$ ) of oral paracetamol; those whose temperature was less than $38.0^{\circ} \mathrm{C}$ were not treated with an antipyretic at this stage. Paracetamol was the chosen antipyretic as single or repeated therapeutic doses of this drug have no effect on the respiratory system. ${ }^{2}$

Each child was then examined by a paediatrician. A blood sample was obtained for measurement of the packed cell volume and the preparation of a thick blood film that was examined for malaria parasites. A chest radiograph was taken and reviewed subsequently by a paediatric radiologist unaware of the clinical details of the study child. Chest radiographs were reported as radiographic pneumonia, other radiological abnormality consistent with an acute lower respiratory tract infection, or normal.

One to two hours after arrival, respiratory rate and temperature were again recorded before the child's departure for home or admission to Basse health centre.

Children were classified into one of three groups on the basis of clinical examination, chest radiograph, and thick blood film results. Group A: pneumonia - radiographic pneumonia and a 
blood film negative for malaria. Group B: malaria - fever or a history of fever, parasitaemia $2500 / \mu \mathrm{l}$ or greater, no radiographic evidence of lower respiratory disease, and no other obvious cause of fever on clinical examination. Group C: miscellaneous - children in neither group A or group $\mathbf{B}$.

These case definitions for pneumonia (group A) and malaria (group B) were chosen to enable an objective comparison of polarised groups of children with either pneumonia or malaria. Thus, a radiological 'gold standard' diagnosis was used for pneumonia and children with malaria parasitaemia were excluded, while, for malaria, a parasitaemia of $2500 / \mu \mathrm{l}$ or greater was chosen as, in the study area, a child with this level of parastaemia and fever but with no other obvious cause may, with reasonable confidence, be diagnosed as having malaria.

Group means were compared using $t$ tests or analysis of variance where appropriate. Contingency tables for categoric variables were compared using a $\chi^{2}$ test, with Yates's correction where necessary. Regression analysis to predict the effect of temperature change on respiratory rate change was performed for the various diagnostic groups seperately and also for these groups combined. The regression constant represents a temperature independent effect, while the regression slope represents a temperature dependent effect on change in respiratory rate over the interval between observations.

\section{Results}

STUDY CHILDREN

Two hundred and five children aged 2 months to 5 years were recruited; satisfactory thick blood films and chest radiographs were obtained from 186 children $(91 \%)$ whose features are described below. Sixty study children satisfied the diagnostic criteria for pneumonia (group A) and 44 the criteria for malaria (group B). The miscellaneous group (group C) comprised the remaining 82 children, and included 21 children with radiographic pneumonia or other radiographic abnormalities and parasitaemia, 15 with other radiographic abnormalities and a negative blood film, and 21 with a normal chest radiograph and a positive blood film associated with another infection or with a parasitaemia of less than 2500 / $\mu l$. The remaining 25 children in group $C$ had a normal chest radiograph and a negative blood film, including five with a clinical diagnosis of pneumonia based on abnormal auscultatory findings, three with other lower respiratory disease,

Table 1 Mean $(S D)$ respiratory rates and temperatures in 186 sick children with tachypnoea on presentation and one to two hours later. One hundred and fifty three children received a single treatment with paracetamol

\begin{tabular}{|c|c|c|c|c|}
\hline \multirow[b]{2}{*}{ Diagnostic group } & \multicolumn{2}{|c|}{ Respiratory rate (bpm) } & \multicolumn{2}{|c|}{ Temperature $\left({ }^{\circ} \mathrm{C}\right)$} \\
\hline & Initial & Final & Initial & Final \\
\hline $\begin{array}{l}\text { Age } 2-11 \text { months } \\
\text { A. Pneumonia }(n=29) \\
\text { B. Malaria }(n=9) \\
\text { C. Miscellaneous }(n=30) \\
\text { Age } 12-59 \text { months }\end{array}$ & $\begin{array}{l}65 \cdot 1(11 \cdot 4) \\
68 \cdot 0(14 \cdot 5) \\
62 \cdot 7(9 \cdot 6)\end{array}$ & $\begin{array}{l}59 \cdot 7(12 \cdot 8) \\
54 \cdot 6(15 \cdot 0) \\
59 \cdot 0(10 \cdot 0)\end{array}$ & $\begin{array}{l}38 \cdot 2(1 \cdot 14) \\
39 \cdot 0(1 \cdot 28) \\
38 \cdot 1(1 \cdot 12)\end{array}$ & $\begin{array}{l}37 \cdot 3(0 \cdot 65) \\
37 \cdot 2(0 \cdot 71) \\
37 \cdot 2(0 \cdot 65)\end{array}$ \\
\hline $\begin{array}{l}\text { A. Pneumonia }(n=31) \\
\text { B. Malaria }(n=35) \\
\text { C. Miscellaneous }(n=52)\end{array}$ & $\begin{array}{l}56 \cdot 1(9 \cdot 8) \\
57.9(8 \cdot 0) \\
53.9(8 \cdot 5)\end{array}$ & $\begin{array}{l}51 \cdot 0(10 \cdot 4) \\
52 \cdot 3(10 \cdot 8) \\
46 \cdot 5(9 \cdot 7)\end{array}$ & $\begin{array}{l}38 \cdot 1(1 \cdot 13) \\
38 \cdot 7(0 \cdot 95) \\
38 \cdot 4(0 \cdot 94)\end{array}$ & $\begin{array}{l}37 \cdot 2(0 \cdot 79) \\
37 \cdot 6(0 \cdot 79) \\
37 \cdot 6(0 \cdot 74)\end{array}$ \\
\hline
\end{tabular}

Table 2 Temperature dependent and independent reduction in respiratory rate in three groups of sick children observed over a one to two hour period

\begin{tabular}{lll}
\hline $\begin{array}{l}\text { Diagnostic } \\
\text { group }\end{array}$ & $\begin{array}{l}\text { Temperature } \\
\text { dependent } \\
\text { effect }\left(\mathrm{bpm} /{ }^{\circ} \mathrm{C}\right)\end{array}$ & $\begin{array}{l}\text { Temperature } \\
\text { independent } \\
\text { effect }(\mathrm{bpm})\end{array}$ \\
\hline A. Pneumonia & $3 \cdot 4$ & $2 \cdot 2$ \\
B. Malaria & $4 \cdot 0$ & $2 \cdot 2$ \\
C. Miscellaneous & 3.8 & $2 \cdot 9$ \\
\hline
\end{tabular}

one with meningitis, four with septicaemia, six with upper respiratory tract infections, and six with other conditions such as urinary tract infections, soft tissue or serious skin infections.

Mean ages for children in the three groups were $15 \cdot 3,21 \cdot 9$, and $18 \cdot 3$ months respectively. Pulse oximetry was performed on 164 children and packed cell volume measured in 174 children. Admission to Basse health centre was required for $54(29.0 \%)$ of the children described, including $25(41 \cdot 7 \%)$ of the children classified as having pneumonia, and nine $(20.5 \%)$ of those classified as having malaria, two of whom required a blood transfusion.

\section{INITIAL OBSERVATIONS}

An initial temperature of $38.0^{\circ} \mathrm{C}$ or greater was recorded in 122 children, 33 of whom were classified as having pneumonia and 35 as having malaria. Children with malaria had a higher mean temperature than children with pneumonia and, in the case of children over the age of 12 months, this difference was statistically significant $(t=2 \cdot 37 ; \mathrm{p}=0 \cdot 02$; table 1$)$. Initial respiratory rates were similar in children with malaria or pneumonia (table 1). Children with pneumonia were hypoxic (oxygen saturation $<95 \%$ ) more frequently than children with malaria $(17 / 58 v 2 / 28)\left(\chi^{2}=4 \cdot 2,1 \mathrm{df} ; \mathrm{p}=0.04\right)$ but initial respiratory rate and temperature were not significantly related to oxygen saturation. The mean (SD) packed cell volume of children with malaria at $23 \cdot 7(6 \cdot 3) \%$ was significantly lower than that of children with pneumonia at $27 \cdot 0$ $(6.8) \%(t=2.5 ; \mathrm{p}=0.015)$, but neither initial temperature nor respiratory rate was correlated significantly with packed cell volume.

\section{CHANGES IN TEMPERATURE AND RESPIRATORY} RATE

One to two hours after presentation a fall in temperature was recorded in 153 children and a temperature rise in 22 while in the remainder the temperature remained unchanged. During the same period the respiratory rate fell in 133 , increased in 37, and showed no change in 16.

For the group of 186 children as a whole there was a temperature independent decrease in respiratory rate of 2.6 breaths per minute (bpm). In addition there was a temperature dependent decrease of $3.7 \mathrm{bpm} /{ }^{\circ} \mathrm{C}$ fall in temperature. A similar relationship was found for each of the three groups, with no significant difference in either the temperature independent or the temperature dependent effect between the different groups (table 2). Whether or not a child received paracetamol had no significant effect on 
the relationship between respiratory rate and temperature other than that due to its effect on temperature.

The level of oxygen saturation did not significantly affect the relationship between temperature and respiratory rate in any of the groups. However, the value of the packed cell volume had a significant effect on the relationship between respiratory rate and temperature for children with malaria. The temperature independent effect became significantly less $(-1.37 \mathrm{bpm}, \mathrm{p}=0.002)$, while the temperature dependent effect became significantly greater $\left(+0.75 \mathrm{bpm} /{ }^{\circ} \mathrm{C}, \mathrm{p}=0.003\right)$, for each one percent decrease in packed cell volume. This relationship with packed cell volume was not found for children in the other diagnostic groups.

\section{FINAL OBSERVATIONS}

Mean values for final temperature and respiratory rate were similar for children in each of the three groups (table 1). Mean final respiratory rates remained above WHO thresholds for the diagnosis of pneumonia in all the groups; $49 / 60$ $(82 \%)$ of children with pneumonia, and $35 / 44$ (80\%) with malaria had raised final respiratory rates. For children who received paracetamol, the corresponding figures were $26 / 33$ (79\%) for those with pneumonia and $28 / 35(80 \%)$ for those with malaria.

A final respiratory rate below WHO thresholds for the diagnosis of pneumonia was recorded for 36 children of whom $35(97 \cdot 2 \%)$ had a fall in temperature. The respiratory rate of 11 children with pneumonia fell to below the WHO levels, representing $23.4 \%$ of the 47 children with pneumonia who had a fall in temperature.

\section{Discussion}

This study has shown that, in children, a raised respiratory rate is a feature of a variety of acute infections, including malaria. It seems likely that the tachypnoea of such children is due, at least in part, to fever. This view is supported by experimental data on the effects of body temperature on respiratory rate, ${ }^{3}$ and also by the results of a previous community study undertaken in the Gambia that showed that respiratory rate increased by approximately $2.5 \mathrm{bpm} /{ }^{\circ} \mathrm{C}$ increase in temperature. ${ }^{4}$

Precise measurement of body temperature is a controversial subject as there are inherent inaccuracies whether the temperature is measured in the axilla or rectally. In this study axillary temperatures were used. However, in a current study further investigating the effect of reduction in body temperature on the respiratory rate, we have measured simultaneously the axillary and rectal temperatures of children comparable with those described in the present paper and found a similar result for the effect of temperature on respiratory rate whether the temperature is measured in the axilla or the rectum (T J D O'Dempsey et al, unpublished).

Whether, in children with acute infections, fever is a direct cause of tachypnoea, or whether both fever and tachnypnoea reflect some other basic physiological change associated with infec- tion, such as increased cytokine production, remains to be determined. The fact that respiratory rates remained raised in many children in the present study after their temperature had been restored to normal by treatment with paracetamol is in keeping with a role for cytokines.

The extent to which the respiratory rate is dependent upon temperature in children with malaria appears to be related to the degree of anaemia. The more anaemic the child, the greater the effect of temperature on respiratory rate. This may reflect increased metabolic demands at higher body temperatures.

Other pathophysiological processes that might result in a raised respiratory rate in patients with severe malaria include lactic acidosis, ${ }^{5}$ cytoadherence of parasitised red blood cells to pulmonary endothelial cells accompanied by septal interstitial oedema ${ }^{6}$ disseminated intravascular coagulation resulting in acute pulmonary insufficiency associated with clinical and radiological signs of pulmonary oedema, ${ }^{7}$ and pulmonary oedema due to renal and left ventricular failure or parenteral fluid overload. ${ }^{8}$ Apart from two children with severe anaemia who required blood transfusion, none of the children classified as having malaria in the present study required anything other than standard treatment for malaria with chloroquine and there were no deaths, either among children who were admitted or among those treated as outpatients. Thus, only two of the children classified as having malaria in this study were considered to have severe malaria.

We anticipated that a substantial component of the raised respiratory rate seen in children with pneumonia would be due to compromised pulmonary function in contrast to children with malaria in whom fever might be expected to be the most important contributory factor. Thus, we expected that treatment of fever would be more effective in reducing the respiratory rate of children with malaria than that of children with pneumonia. This proved not to be the case and respiratory rates fell in a similar manner in both groups.

Thus, reduction of body temperature does not help to distinguish children with malaria and a raised respiratory rate from those with pneumonia. Furthermore, a reduction in temperature may cause an associated reduction in respiratory rate to a level that is below WHO thresholds for the diagnosis of pneumonia, as noted for one fifth of the children with pneumonia in this study. Therefore, a history of recent administration of an antipyretic or other measures to control fever may be important when evaluating children for possible pneumonia.

We wish to thank the staff at MRC Basse field station, our colleagues in the department of medical and health in Upper River Division, and the children and parents who took part in this study. We are grateful to Drs Harry Campbell and Peter Byass for their We are grateful to Drs Harry Campbell and Peter Byass for their helpful comments. This study was performed during the

1 World Health Organisation. Acute respiratory infections in 'children: case management in small hospitals in developing countries. (WHO/ARI/90.5.) Geneva: WHO, 1990.

2 Flower RJ, Moncada S, Vane JR. Analgesic-antipyretics and 
anti-inflammatory agents. In: Gilman AG, Goodman LS, Rall TW, Murad F, eds. The pharmacological basis of therapeutics. New York: Macmillan, 1985: 674-715.

3 Cooper KB, Veale WL. Effects of temperature on breathing. In: Fenn WO, Rahn H, eds. Handbook of physiology. Section 3, vol II. The respiratory system. Washington DC: American 3, vol II. The respiratory system. Wash
Physiological Society, 1986: $691-702$.

4 Campbell H, Byass P, O'Dempsey TJ. Effect of body temperature on respiratory rate in young children. Arch Dis Child 1992; 67: 664 .

5 White NJ, Warrell DA. The management of severe malaria

In: Wernsdorfer WH, McGregor I, eds. Malaria. Vol I.
Edinburgh: Churchill Livingstone, 1988: 865-88.

6 Corbett CEP, Duarte MIS, Lancellotti CLP, Silva MALG, Andrade HF. Cytoadherence in human falciparum malaria as a cause of respiratory distress. F Trop Med Hyg 1989; 92: 11220.

7 Punyagupta S, Srichaikul T, Nitiyanant P, Petchlai B. Acute pulmonary insufficiency in falciparum malaria: summary of 12 cases with evidence of disseminated intravascular coagulation. Am $\mathcal{F}$ Trop Med Hyg 1974; 23: 551-9.

8 Harinasatu T, Bunnag D. The clinical features of malaria. In: Wernsdorfer WH, McGregor I, eds. Malaria. Vol I. Edinburgh: Churchill Livingstone, 1988: 709-35.

\section{Computed tomography in acute bacterial meningitis}

One of the factors that determines whether an investigation is done is the ease of its availability. This is particularly important when the patient is acutely ill and the investigation can only be done in another hospital. Clearly in such circumstances the risk involved in moving the patient must be balanced against the potential benefit to be derived from the investigation. Until recently in Britain computed tomography was available at only a relatively few hospitals and this clinical decision needed to be taken fairly frequently but as more hospitals acquire the facility so the risks of transfer over a long distance enter into the equation less often. Nevertheless the question still needs to be asked, 'Is a CT scan likely to be helpful?'

Between January 1986 and October 1989, 33 children with acute bacterial meningitis were transferred from other hospitals to the Hospital for Sick Children, Great Ormond Street, for computed tomography. Robert Heyderman and his colleagues have recently described the clinical and radiological features of 30 of these patients (Developmental Medicine and Child Neurology 1992; 34: 870-5).

The findings on computed tomography significantly influenced management in three patients. One 18 month old child referred because of clinically suspected raised intracranial pressure was shown to have gross communicating hydrocephalus and a ventriculoperitoneal shunt was inserted. Of the other two patients one had a subdural empyema and the other a large subdural effusion, both needing surgery. These two children had both developed progressive focal neurological signs. Patients with non-progressive focal neurological signs were not helped by the scanning. Similarly the investigation was unhelpful in the management of patients with repeated seizures $(n=3)$ or prolonged fever $(n=8)$. Three patients in this series were shown to have a cerebral infarct but none of them had focal neurological signs. Fifteen children were suspected to have raised intracranial pressure on clinical grounds and five of these showed brain oedema on scanning. Four of these five had signs of brainstem death soon after transfer.

The authors conclude that computed tomography is usually not helpful in the management of children with acute bacterial meningitis and it can not be used to eliminate the risk of coning when considering whether to perform a lumbar puncture. Most children with meningitis do not need computed tomogram ( $c f$ tuberculous meningitis, see Archivist 1991 pages 151 and 1226). The main indication for the investigation is a progressive focal neurological deficit but I suspect that many children with impaired consciousness will continue to be scanned, especially when the investigation is available on the spot. This paper provides no information about the value of neurological intensive care including intracranial pressure monitoring. 